\title{
METODE
}

\section{UGOTAVLJANJE INTENZIVNOSTI GEOMORFNIH PROCESOV S POMOČJO POSNETKOV CIKLIČNEGA AEROFOTOGRAFIRANJA SLOVENIJE}

\author{
AVTORJA \\ dr. Mihaela Triglav Čekada \\ Geodetski inštitut Slovenije, \\ Jamova 2, SI - 1000 Ljubljana, Slovenija \\ mihaela.triglav@gis.si
}

\section{dr. Matija Zorn}

Znanstvenoraziskovalni center Slovenske akademije znanosti in umetnosti, Geografski inštitut Antona Melika, Gosposka ulica 13, SI - 1000 Ljubljana, Slovenija

matija.zorn@zrc-sazu.si

DOI: $10.3986 / G V 86206$

UDK: 551.4.037:528.715(497.4)

COBISS: 1.01

\section{IZVLEČEK}

Ugotavljanje intenzivnosti geomorfnih procesov s pomočjo posnetkov cikličnega aerofotografiranja Slovenije

Za območje Slovenije obstaja dolgoleten niz letalskih posnetkov cikličnega aerofotografiranja Slovenija (CAS). Njihova uporaba je bila v geografiji med drugim povezana s spremembami rabe tal, s preučevanjem degradacije okolja, pa tudi za ugotavljanje nekaterih naravnogeografskih sprememb v pokrajini, na primer za ugotavljanje sprememb ledenikov ali za premikanja rečnih strug. V članku predstavljamo uporabnost CAS za spremljanje intenzivnosti pobočnih procesov. $Z$ njihovo pomočjo smo izmerili velikost dveh skalnih podorov: podor slapu Čedca v Kamniško-Savinjskih Alpah ter odlom na pobočju Glave pod Triglavom. Poleg tega smo ugotavljali reliefne spremembe na melišču Birški plaz pod Velikim vrhom na Košuti ter v hudourniški dolini potoka Suhelj v Zgornjesavski dolini.

\section{KLJUČNE BESEDE}

geomorfni procesi, ciklično aerofotografiranje, aerolasersko skeniranje, slap Čedca, Birški plaz, potok Suhelj, Glava pod Triglavom, Slovenija 


\begin{abstract}
Determining the intensity of geomorphic processes using cyclical aerial photogrammetric measurements of Slovenia

A set of cyclical aerial photogrammetric measurements of Slovenia (CAS) taken over the course of many years is available. Among other things, their use in geography has been connected with exploring changes in land use, studying environmental degradation, and determining specific physical geographical changes in the landscape, such as changes in glaciers and river beds. This article presents the usefulness of CAS for monitoring the intensity of slope processes. CAS stereoimages were used to measure the size of two rockfalls: one at Čedca Falls in the Kamnik-Savinja Alps and one on the slopes of Mt. Glava below Mt. Triglav. Also studied were terrain changes on the Birški plaz talus below Mt. Veliki Vrh on the Košuta Ridge in the Karavanks, and in the torrent valley of Suhelj Creek in the Upper Sava Valley.
\end{abstract}

\title{
KEY WORDS
}

geomorphic processes, cyclical aerophotogrammetry, aerial laser scanning, Čedca waterfall, Birški plaz, Suhelj stream, Mount Glava, Slovenia

Uredništvo je prispevek prejelo 25. septembra 2014. 


\section{Uvod}

Za območje Slovenije obstaja dolgoleten niz letalskih posnetkov cikličnega aerofotografiranja Slovenija (CAS) (Oštir 2006; Breg Valjavec in Ribeiro 2014), ki ga hrani Geodetska uprava Republike Slovenije (GURS). Uporaba posnetkov CAS pa tudi drugih letalskih posnetkov je bila v geografiji med drugim povezana s spremembami rabe tal (na primer Petek, Bric in Rotar 2002), s preučevanjem degradacije okolja (na primer Breg 2013; Kokalj in Veljanovski 2014), uporabljeni po so bili tudi za ugotavljanje nekaterih naravnogeografskih sprememb v pokrajini, na primer za ugotavljanje sprememb ledenikov (Triglav Čekada, Zorn in Colucci 2014) ali za ugotavljanje premikanja rečnih strug (na primer Breg 2007). Sicer obstajajo natančnejše metode snemanja površja, s katerimi lahko ugotavljamo intenzivnost geomorfonih procesov (Triglav Čekada 2011), a smo se zaradi dolgoletnega niza posnetkov CAS odločili, da preverimo njihovo uporabnost za spremljanje pobočnih procesov (Komac in Zorn 2007). Z njihovo pomočjo smo izmerili velikost dveh skalnih podorov: podor slapu Čedca v Kamniško-Savinjskih Alpah ter odlom na pobočju Glave pod Triglavom. Poleg tega smo z njihovo pomočjo ugotavljali reliefne spremembe na melišču Birški plaz pod Velikim vrhom na Košuti v Karavankah ter v hudourniški dolini potoka Suhelj v Zgornjesavski dolini.

\section{Metodologija}

Primerjali smo dva niza digitalnih posnetkov CAS - za leti 2006 in 2011. V času med obema snemanjema smo v Sloveniji prešli v nov horizontalni državni koordinatni sistem - iz koordinatnega sistema D48/GK v D96/TM koordinatni sistem (Berk in Komadina 2010; Berk, Komadina in Triglav 2011), kar smo pri uporabi orientacijskih podatkov aeroposnetkov morali upoštevati. S pomočjo posnetkov smo izdelali digitalne modele reliefa (DMR) z velikostjo celice $5 \times 5 \mathrm{~m}$. Kljub temu, da že obstajajo samodejni postopki slikovnega ujemanja, ki omogočajo samodejno izdelavo DMR-jev, tovrstni DMR-ji ne dosežejo takšne višinske natančnosti kot ročni stereofotogrametrični zajem (Gruen 2012). Zato smo vse DMR-je ročno zajeli na digitalnih fotogrametričnih postajah s klasičnim stereofotogrametričnim postopkom (Kraus 1993).

Za območja zajema smo izdelali pravilno mrežo točk z velikostjo celice $5 \times 5 \mathrm{~m}$. Orientacijski parametri posnetkov CAS 2006 so bili izračunani v okviru aerotriangulacije celotnega fotogrametričnega bloka in so zapisani v koordinatnem sistemu D48/GK z nadmorskimi višinami. Mrežo točk smo transformirali tudi v nov koordinatni sistem, da smo lahko izvedli izmero na istih točkah tudi na stereoposnetkih CAS 2011, ki imajo orientacijske parametre zapisane v koordinatnem sistemu D96/TM. Rezultate izmere iz CAS 2011 smo transformirani v stari koordinatni sistem D48/GK, v katerem smo izvedli primerjavo razlik višin. Transformacije med D48/GK in D96/TM so bile izvedene z uporabo modela trikotniške transformacije (različica 3.0), ki omogoča zveznost na območju celotne države in povratnost transformacij (Berk in Komadina 2010; 2013). Transformacija zagotavlja natančnost večjo od enega decimetra (koordinatni standardni odklon je okrog $3 \mathrm{~cm}$ ) (Berk, Komadina in Triglav 2011). Ločljivost aeroposnetkov CAS 2006 na obravnavanih območjih je $0,5 \mathrm{~m}$, pri CAS 2011 pa 0,25 m.

Kot smo omenili zgoraj, smo višine na točkah merili ročno, saj to omogoča izmero višin na odprtem nezaraščenem terenu $\mathrm{z}$ natančnostjo nekaj decimetrov (za natančnost izmere $\mathrm{v}$ stereomodelu glej sklep). Točke mreže predstavljajo DMR, zato smo na območjih z rastjem višine spuščali ročno za ocenjeno višino dreves. Tovrstno spuščanje višin je vzrok večine napak pri DMR-jih. V našem primeru se pojavljajo ob robovih obravnavanih območij. Napake pri določanju višin se lahko pojavijo tudi tam, kjer je detajl, ki ga merimo, $v$ senci, saj je stereoefekt $v$ takšnih primerih zelo slab (težko prepoznamo isto podrobnost). Napake višin zaradi položajne zaokrožitve točk DMR na pravilno mrežo pa se pojavljajo tudi na zelo strmih območjih (na primer vrhovi gora, stene), saj položajna napaka $0,5 \mathrm{~m}$ zelo hitro povzroči velike višinske razlike. 
Zaradi večje natančnosti smo pri skalnem odlomu na pobočju Glave pod Triglavom uporabili zelo natančen DMR $1 \times 1 \mathrm{~m}$, izdelan na podlagi aerolaserskega skeniranja okolice Triglava iz leta 2012 (Triglav Čekada in sodelavci 2013). Za ostala obravnavana območja bo to mogoče, ko bo končano aerolaserskega skeniranje celotnega slovenskega ozemlja (Triglav Čekada, Bric in Oven 2012; Pegan Žvokelj, Bric in Triglav Čekada 2014).

Preglednica 1: Osnovni podatki o uporabljenih posnetkih.

\begin{tabular}{|c|c|c|c|c|}
\hline območje & snemanje & $\begin{array}{l}\text { fotogrametrični blok (številka } \\
\text { fotogrametričnega bloka) }\end{array}$ & $\begin{array}{l}\text { datum } \\
\text { snemanja }\end{array}$ & $\begin{array}{l}\text { označba CAS } \\
\text { stereoposnetka } \\
\text { oziroma opomba }\end{array}$ \\
\hline slap Čedca & CAS 2006 & Jezersko (15) & 21.7 .2006 & $\begin{array}{l}\text { C06_15_0108, } \\
\text { C06_15_019 }\end{array}$ \\
\hline slap Čedca & CAS 2011 & Kranj (09) & 29.6 .2011 & $\begin{array}{l}\text { AF11_09_0458, } \\
\text { AF11_09_0459 }\end{array}$ \\
\hline potok Suhelj & CAS 2006 & Mojstrana (05) & 22.7 .2006 & $\begin{array}{l}\text { C06_5_0025 } \\
\text { C06_5_0026 }\end{array}$ \\
\hline potok Suhelj & CAS 2011 & Bovec (11) & 11.8 .2011 & $\begin{array}{l}\text { AF11_11_0007 } \\
\text { AF11_11_0008 }\end{array}$ \\
\hline Birški plaz & CAS 2006 & Radovljica (14) & 20.7 .2006 & $\begin{array}{l}\text { C06_14_0026 } \\
\text { C06_14_0027 }\end{array}$ \\
\hline Birški plaz & CAS 2011 & Kranj (09) & 29.6 .2011 & $\begin{array}{l}\text { AF11_09_0255 } \\
\text { AF11_09_0256 }\end{array}$ \\
\hline Glava & CAS 2006 & Bled (13) & 22.7 .2006 & $\begin{array}{l}\text { C06_13_0082 } \\
\text { C06_13_0083 }\end{array}$ \\
\hline Glava & $\begin{array}{c}\text { aerolasersko } \\
\text { snemanje (2012) }\end{array}$ & testno območje Triglav & 18.9 .2012 & $\begin{array}{l}\text { aerolasersko snemanje } \\
\text { izvedeno v okviru medna- } \\
\text { rodnega projekta Naravne } \\
\text { nesreče brez meja - NH-WF } \\
\text { (Triglav Čekada in sodelavci } \\
\text { 2013; Naravne ... 2014). }\end{array}$ \\
\hline
\end{tabular}

\section{Izbrani primeri}

\subsection{Podor slapu Čedca}

Konec maja in junija 2008 je nastalo več skalnih podorov na območju slapu Čedca, ki so preoblikovali steno pred tem najvišjega slapu v Sloveniji z višino $130 \mathrm{~m}$ (Zorn 2012). Po podorih je bil slap visok le še okrog 30 m (Frantar in Robič 2009). Nastal je obsežen podorni vršaj, ki je podvržen fluvialnemu preoblikovanju (slika 1).

Oktobra 2008 so bile izvedene meritve območja podora s terestričnim laserskim skenerjem (Ivnik 2010). Na podlagi razlik med DMR-jem izmerjenim iz stereoposnetkov CAS 2006 in podatki terestričnega laserskega skeniranja je Ivnikova (2010) izmerila prostornino odlomljene gmote na $229.140 \mathrm{~m}^{3}$, prostornino odloženega gradiva pa na $287.317 \mathrm{~m}^{3}$ (razmerje $1: 1,25$ ). V to ni všteto gradivo, ki je bilo v času do meritev že odneseno v nižje lege. Na podlagi prečnih prerezov pobočja (po plastnicah) pred in po 


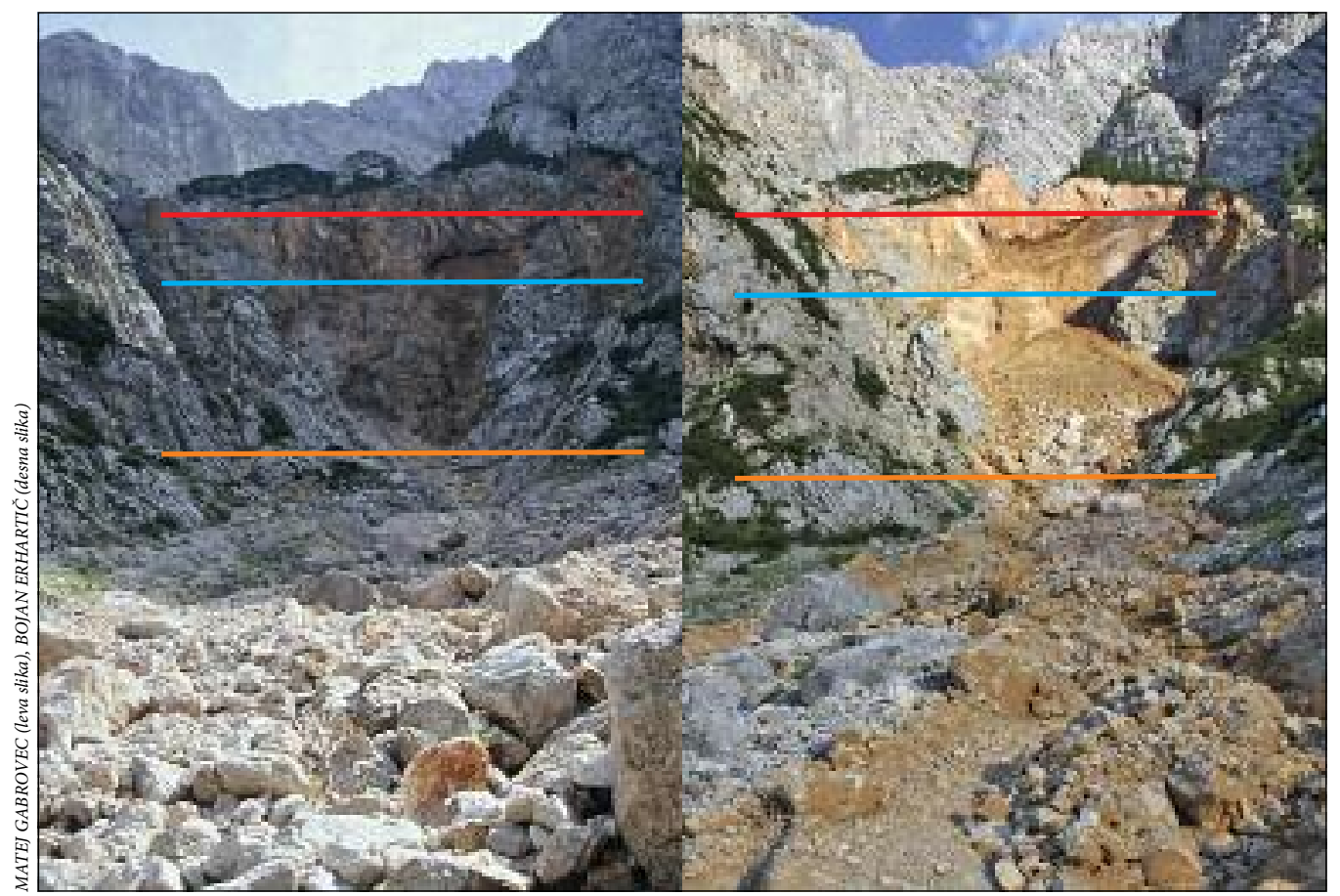

Slika 1: Slap Čedca pred podori leta 2008 in neposredno po njih (Erhartič in Jelenko 2010, 23). Ker posnetka nista narejena iz istega stojišča, smo za lažjo primerjavo dodali tri črte, ki označujejo približno iste prečne prereze.

podorih je bilo ugotovljeno, da je bil največji odmik pobočja v zgornjem delu odlomne ploskve, in sicer $52 \mathrm{~m}$. Vzdolžni prerezi pobočja pred in po podorih pa so pokazali znižanje površja na območju sprožitve med 30 in $43 \mathrm{~m}$ in zvišanje površja med 12 in $33 \mathrm{~m}$ na območju odlaganja. Na območju sprožitve je bila največja sprememba nadmorske višine $-55 \mathrm{~m}$, na območju odlaganja pa $+44 \mathrm{~m}$ (Ivnik 2010).

Fotogrametrično stereoizmero na stereoparu CAS 2006 smo ponovili in izvedli še novo izmero na stereoparu CAS 2011. Na območju sprožitve smo ugotovili največjo višinsko razliko $-64 \mathrm{~m}$, na območju odlaganja pa $+48 \mathrm{~m}$. Preučili smo tudi spreminjanje reliefa pod podornim vršajem. Na sliki 3 vidimo izvorno območje podora in nasutje ter območje dolvodno. Po naših izračunih se je $\mathrm{z} 0,95$ ha velikega izvornega območja (območje obarvano z vijoličastimi odtenki na sliki 3) odlomilo $288.880 \mathrm{~m}^{3}$ gradiva. Odlomljeno gradivo se je odložilo na 1,89 ha velikem območju (območje obarvano z zelenimi odtenki na sliki 3), njegovo prostornino pa smo izračunali na $271.730 \mathrm{~m}^{3}$. V primerjavi s podatki Ivnikove (2010) je naša vrednost količine odloženega gradiva manjša kot količina sproženega gradiva. To je lahko posledica intenzivnega odnašanja gradiva med obema izračunoma, lahko pa so posredi tudi napake. Kakorkoli pa tolikšna količina nevezanega gradiva lahko v prihodnosti botruje večjim premikom tega gradiva dolvodno.

Model podora in nasutja vidimo na sliki 2, ki prikazuje stranski DMR pogled na "prizadeto « območje.

Na območju po strugi dolvodno opazimo na podlagi slike 3 predvsem odstranjevanje kameninskega gradiva zaradi geomorfnega delovanja vodotoka; večina višinskih razlik je do $-5 \mathrm{~m}$ (na sliki 3 obarvano $\mathrm{z}$ rjavo). Na dveh manjših območjih (na sliki 3 obarvano z zeleno) pa opazimo nasutje do $10 \mathrm{~m}$.

Višinske razlike do $-20 \mathrm{~m}$ ob brežinah potoka so posledica napak v zajemu podatkov. Te so nastale zaradi različne ocene višine dreves, $s$ katerimi smo določali višino površja. Na zelo strmih območjih 


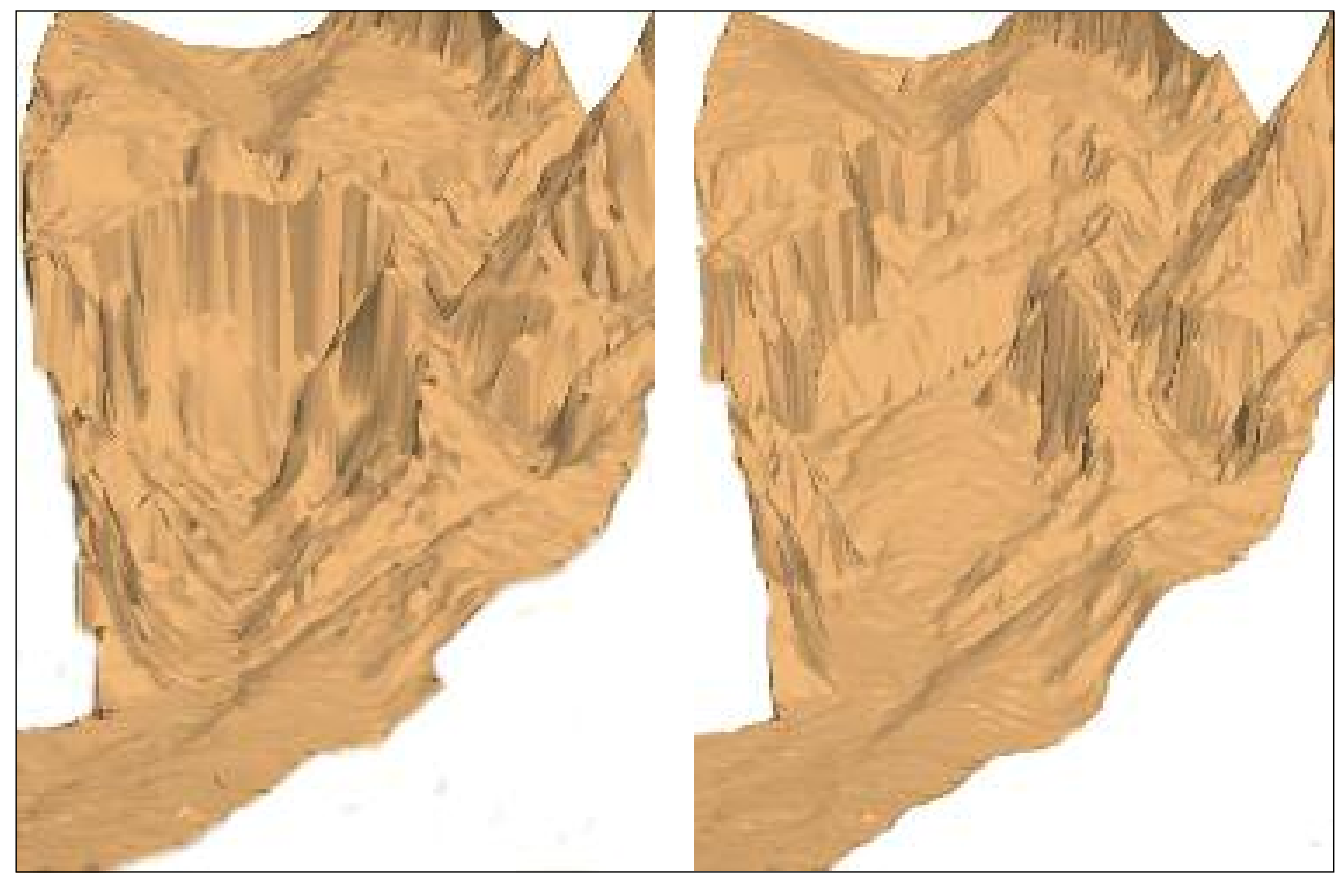

Slika 2: Trirazsežnostni prikaz območja skalnega podora slapu Čedca pred (leta 2006; levo) in po podorih (leta 2011; desno).

nad slapom je prišlo do prepleta napak zaradi zaokroževanja DMR-ja na $1 \mathrm{~m}$ ter zaradi transformacije točk med koordinatnima sistemoma. Večina teh odstopanj je med $0 \mathrm{~m}$ in $-5 \mathrm{~m}$.

\subsection{Območje Birškega plazu}

Birški plaz je ime za obsežno melišče pod Velikim vrhom (2088 m) na Košuti (slika 4) v Karavankah. Leži pod veliko podorno steno (prek 7 ha) največjega znanega zgodovinskega skalnega podora pri nas, $\mathrm{z}$ ocenjeno prostornino med 20 in 100 milijoni $\mathrm{m}^{3}$. Podor največkrat povezujejo $\mathrm{z}$ beljaškim potresom leta 1348, ko so se sprožili podobno veliki podori z Dobrača ( $2166 \mathrm{~m}$ ) na avstrijskem Koroškem (Zorn 2002a). Zgodovinski viri tega še niso potrdili (Zorn 2002b), so pa z različnimi datacijskimi metodami pokazali, da je podor nastal v poznem srednjem veku (Mrak 2004; Merchel in sodelavci 2014).

Preučevano območje (slika 5) meri 40 ha. V večjem delu gre za aktivno melišče. Ob primerjavi DMR-jev 2006 in 2011 smo ugotovili reliefne spremembe do $\pm 10 \mathrm{~m}$. Najbolj očitno je odlaganje gradiva na desnem (vzhodnem) spodnjem delu melišča. Na obsežnejše, 1,1 ha veliko območje (na sliki 5 občrtano s črno), se je v obravnavanem obdobju nasulo $38.240 \mathrm{~m}^{3}$. Na manjše občrtano območje (velikost 0,4 ha) pa se je nasulo $7230 \mathrm{~m}^{3}$.

Količina odloženega gradiva je v obravnavanem obdobju na Birškem plazu veliko manjša od podornega gradiva pod slapom Čedca. To kaže na razmerje med »običajnim« odlamljanjem (velika pogostost procesov ob njihovi manjši jakosti) iz gorskih ostenji in večjimi geomorfnimi dogodki (majhna pogostost procesov ob njihovi večji jakosti) kot je bil podor slapu Čedca.

Povprečno višinsko odstopanje na vseh izmerjenih točkah je 1,5 m. Kot smo omenili že v primeru Čedce, lahko večji del teh višinskih razlik pripišemo napakam, ki nastanejo zaradi zaokroževanja DMR-ja na zelo strmem reliefu. Večja pozitivna in negativna odstopanja ob robovih melišča pripisujemo 


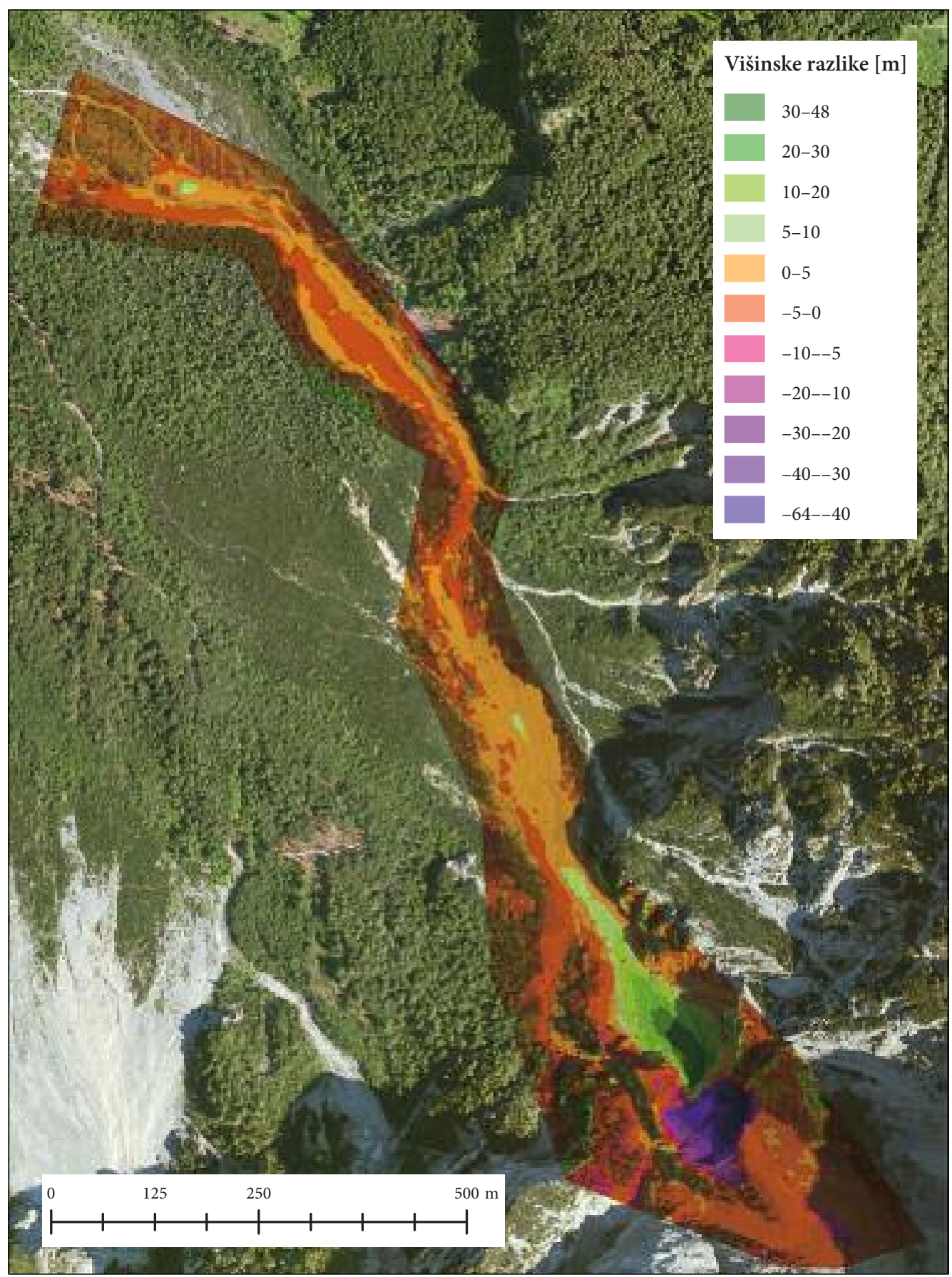

Slika 3: Višinske razlike na območju podora slapu Čedca med letoma 2006 in 2011 na ortofotu iz CAS 2011 (vir ortofota: GURS). 


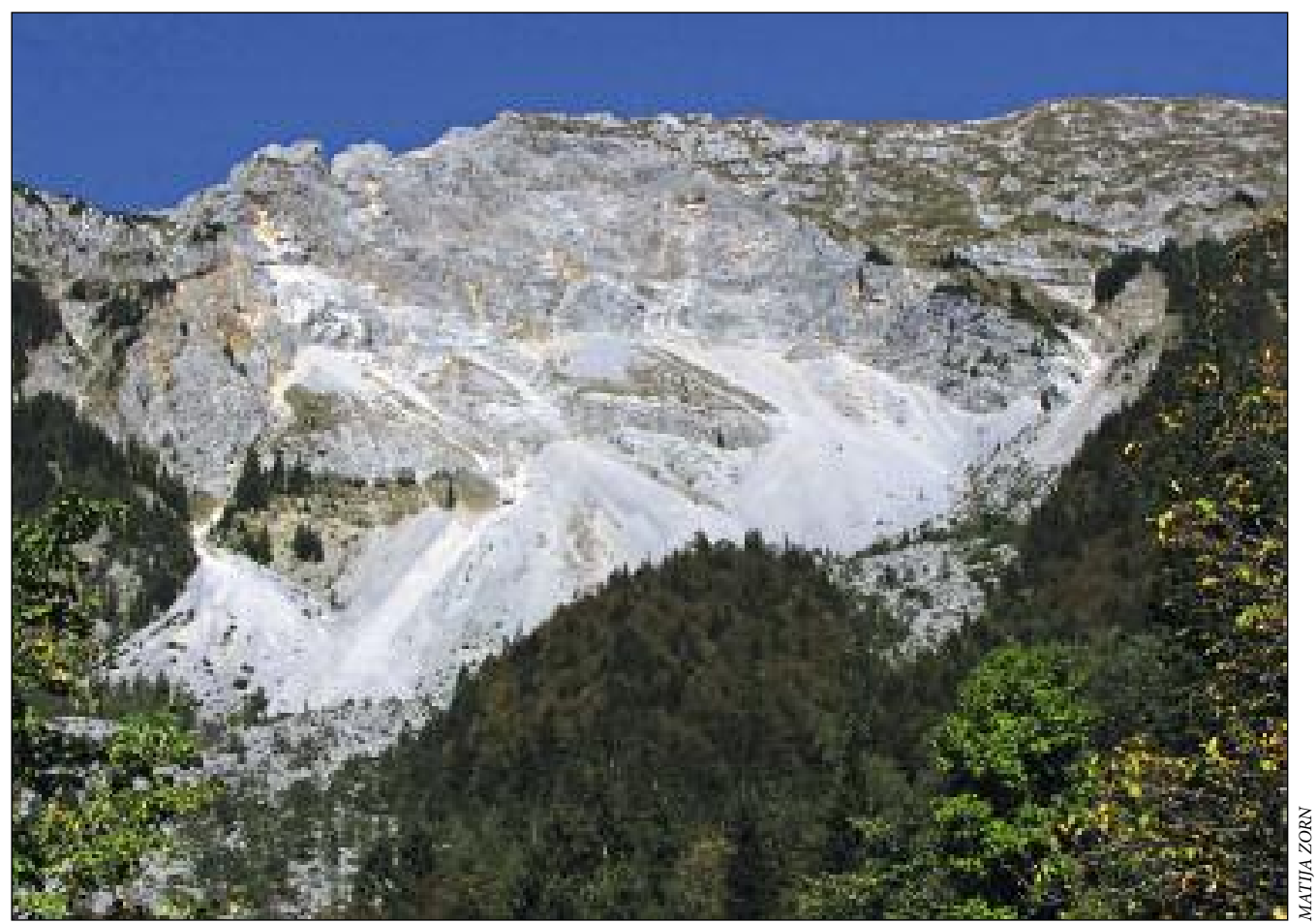

Slika 4: Zgodovinski skalni podor z Velikega vrha na Košuti v Karavankah.

težavam ob stereozajemu iz CAS 2011, saj so bila ta območja v senci, ter napakam zaradi zaokroževanja položaja točk DMR-ja.

\subsection{Hudournik Suhelj}

Porečje potoka Suhelj (levi pritok Save Dolinke pri Podkorenu) sodi med območja z velikim sproščanjem in odplavljanjem kamninskega gradiva (slika 6). V porečju, ki meri $1,9 \mathrm{~km}^{2}$, je sproščanje gradiva ocenjeno na $2960 \mathrm{~m}^{3} / \mathrm{km}^{2}$ letno, odplavljanje pa na $2523 \mathrm{~m}^{3} / \mathrm{km}^{2}$ letno (Mikoš 1995). Zaradi obilice nevezanega gradiva sodi porečje potoka Suhelj med območja z visoko nevarnostjo za proženje drobirskih tokov. Ocenili so, da lahko v porečju pričakujemo drobirske tokove s prostornino tudi prek $35.000 \mathrm{~m}^{3}$ (Sodnik in Mikoš 2006, 119).

Med letoma 2006 in 2011 je bil hudournik Suhelj močno geomorfno aktiven, saj se je relief v njegovem povirnem delu znižal od $4 \mathrm{~m}$ (zgoraj na sliki 7) do celo do $13 \mathrm{~m}$ (spodaj na sliki 7). Relativno visoke vrednosti so verjetno posledica napak zaradi položajnih zaokrožitev točk DMR-ja (glej poglavje 2), katerih določevaje je še posebej zahtevno na zelo strmem reliefu. Precenjena vrednost pride še bolj do izraza pri prostornini odstranjenega gradiva med letoma 2006 in 2011 . Znotraj s črno črto občrtanega območja na sliki 7 (1,3 ha) je bilo odstranjenega kar $98.700 \mathrm{~m}^{3}$ oziroma prek milijona $\mathrm{m}^{3} / \mathrm{km}^{2}$ letno. Samo na dveh črtkanih območjih skupne velikosti 0,15 ha, kjer so višinske razlike največje, tudi do $-15 \mathrm{~m}$, je razlika v prostornini $14.160 \mathrm{~m}^{3}$. To krepko presega zgoraj predstavljene ocene Mikoša (1995), pri čemer levega dela povirja (na desni strani slike 7) sploh nismo obravnavali, saj je bil leta 2006 v senci, kar je oteževalo fotogrametrični stereozajem. Za primerjavo povejmo, da so ocene letnega sproščanja gradiva v vsej Sloveniji nekaj milijonov $\mathrm{m}^{3}$ letno (Zorn 2008). 


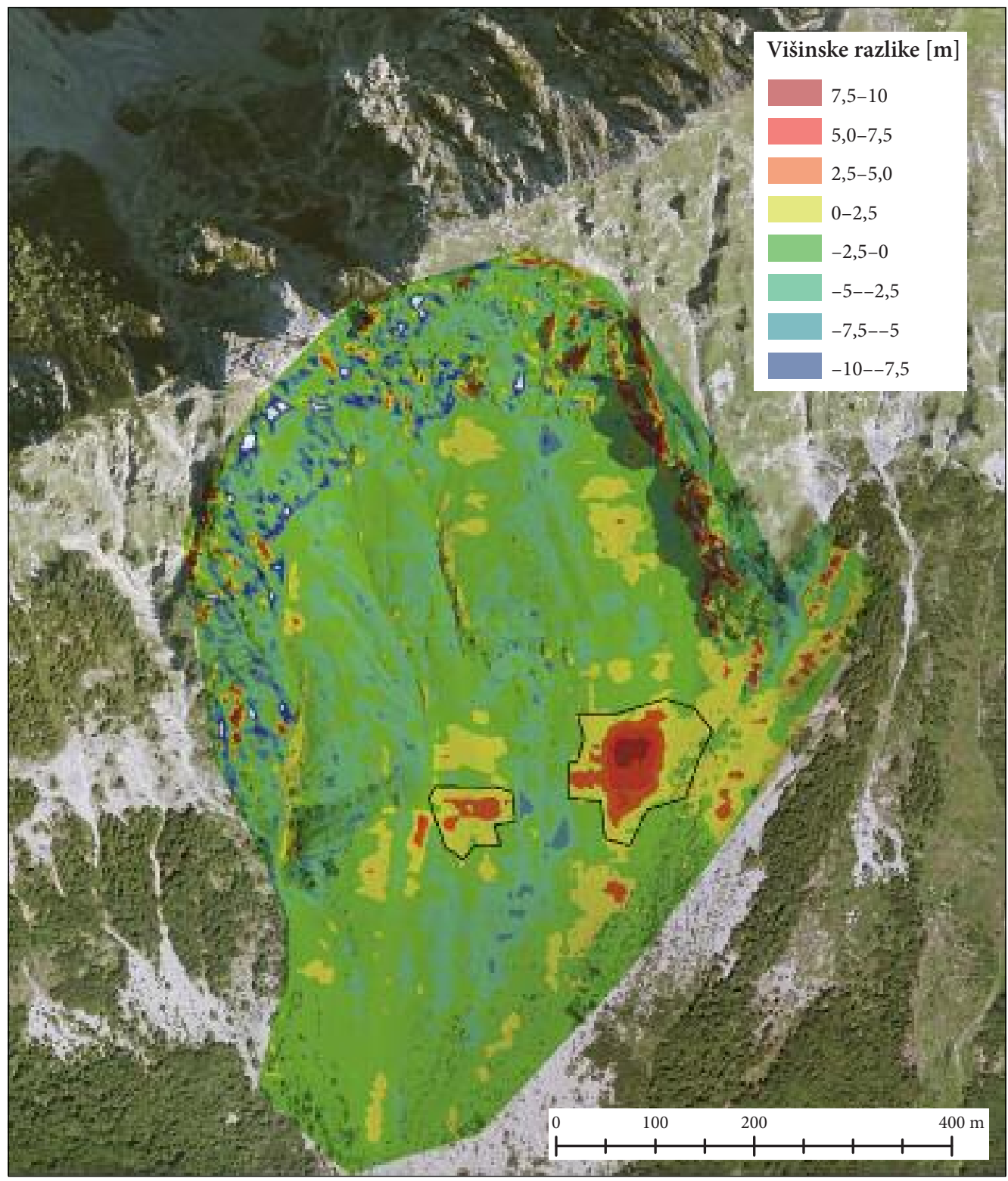

Slika 5: Prikaz višinskih razlik na Birškem plazu med letoma 2006 in 2011 na ortofotu iz leta 2011 (vir ortofota: GURS).

Izračun kaže na težave pri interpretaciji velikostnega reda rezultatov oziroma na napake, ki nastanejo zaradi prostorske ločljivosti, zgoraj omenjenega položajnega zaokroževanja točk DMR-ja ter napak orientacije stereomodela $v$ prostoru. Sama natančnost orientacije stereomodela oziroma natančnost aerotriangulacije je opredeljena $v$ tehnični dokumentaciji za posamezno snemanje CAS (na primer Razpisna ... 2008). Iz dokumentacije je razvidno, da so dovoljena maksimalna višinska odstopanja na 


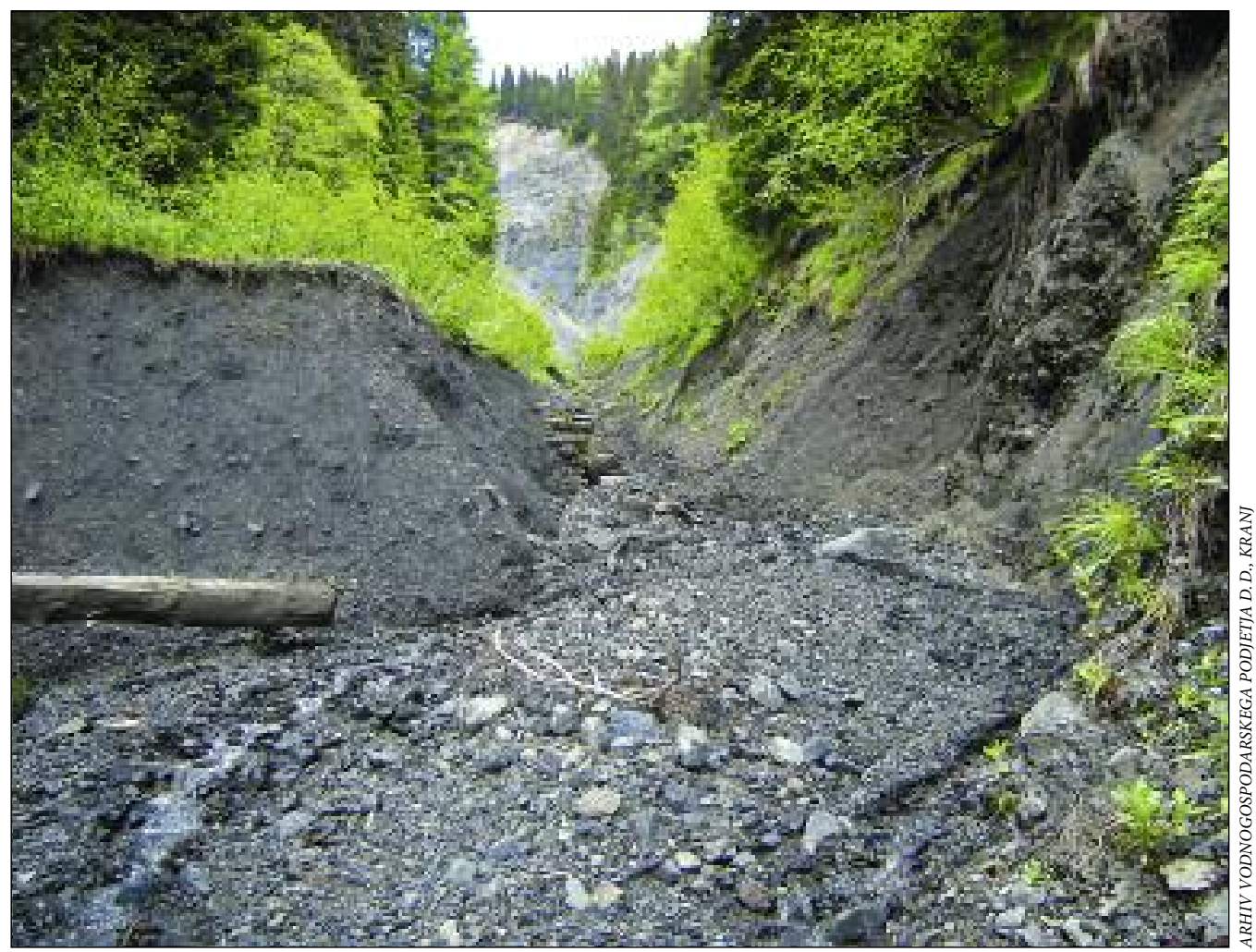

Slika 6: Erozijsko žarišče v povirju potoka Suhelj.

kontrolnih točkah tudi do $1 \mathrm{~m}$. Žal na ožjem območju Suhlja nimamo na razpolago kontrolnih točk, s katerimi bi lahko potrdili tezo o natančnosti posameznega letnika CAS. Na sliki 7 vidimo negativna odstopanja med 0 in $-6 \mathrm{~m}$ tudi na območjih, kjer ne pričakujemo višinskih odstopanj (na spodnjem in zgornjem delu slike). Če predpostavimo, da sta stereomodela samo vertikalno zamaknjena za $3 \mathrm{~m}$, dobimo maksimalne višinske razlike do $-12 \mathrm{~m}$ ter prostornino znotraj 1,3 ha velikega obravnavanega območja $59.030 \mathrm{~m}^{3}$ oziroma $60 \%$ zgoraj omenjene prostornine.

\subsection{Skalni odlom na Glavi pod Triglavom}

Na severnem pobočju Glave $(2426 \mathrm{~m})$ se je leta 2011 podrl del ostenja (sliki 8), kar lahko opazimo na posnetkih CAS 2011 ter posnetkih posebnega aerolaserskega skeniranja iz leta 2012.

V nasprotju z zgornjimi primeri smo tu zaradi dostopnih podatkov aerolaserskega skeniranja lahko primerjali DMR-ja 2006 in $2011 \mathrm{z}$ velikostjo celice $1 \times 1 \mathrm{~m}$, kar omogoča preučevanje sprememb $\mathrm{v}$ prostoru $\mathrm{z}$ večjo prostorsko ločljivostjo. Prvi je bil ročno fotogrametrično zajet iz stereoposnetkov CAS 2006 (slika 10), drugi pa je bil samodejno izdelan iz podatkov aerolaserskega skeniranja okolice Triglava (Triglav Čekada in sodelavci 2013; Naravne ... 2014). DMR aerolaserskega skeniranja smo izdelali na podlagi surovih laserskih podatkov, ki smo jih predhodno transformirali iz koordinatnega sistema D96/TM v D48/GK koordinatni sistem.

Na melišče pod Glavo se je leta 2011 nasula do $5 \mathrm{~m}$ debela plast kamninskega gradiva. Površina nasutja je $158 \mathrm{~m}^{2}$, prostornina pa $124 \mathrm{~m}^{3}$ (slika 9). 


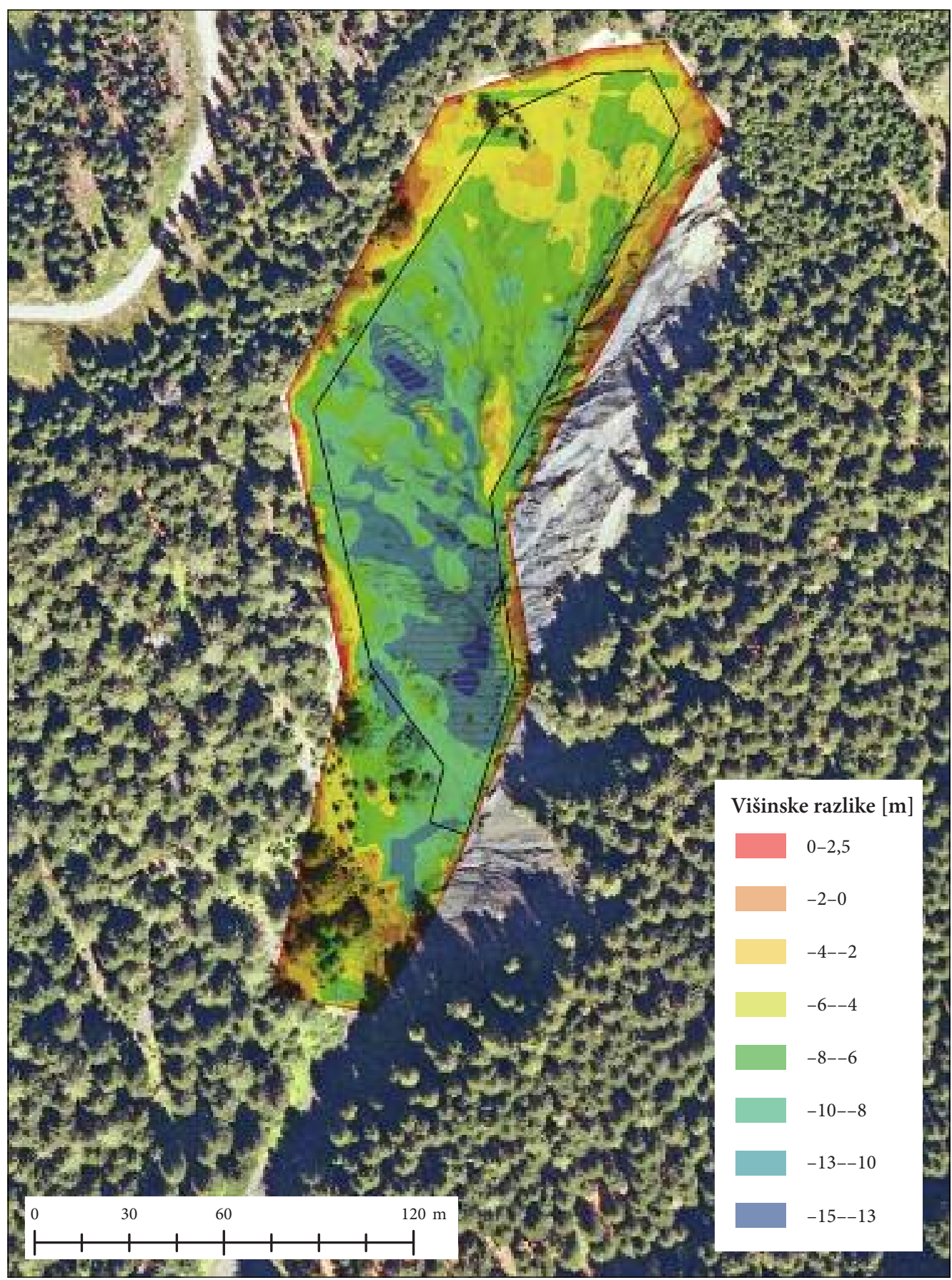

Slika 7: Prikaz višinskih razlik na območju potoka Suhelj med letoma 2006 in 2011 prikazano na ortofoto iz 2011 (vir ortofota: GURS) 
Mihaela Triglav Čekada, Matija Zorn Ugotavljanje intenzivnosti geomorfnih procesov s pomočjo ...

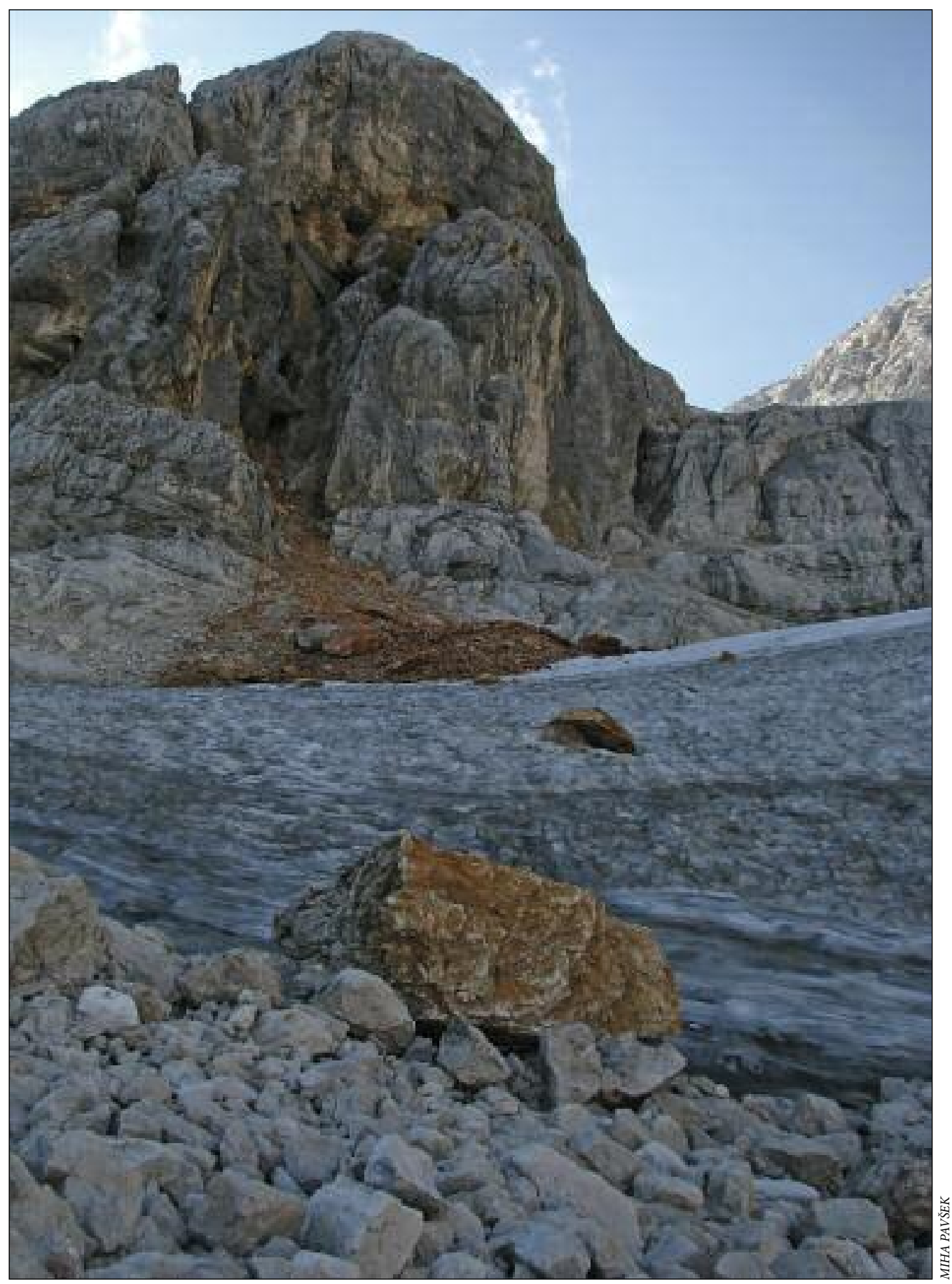

Slika 8: Podor na Glavi pod Triglavom leta 2011. 


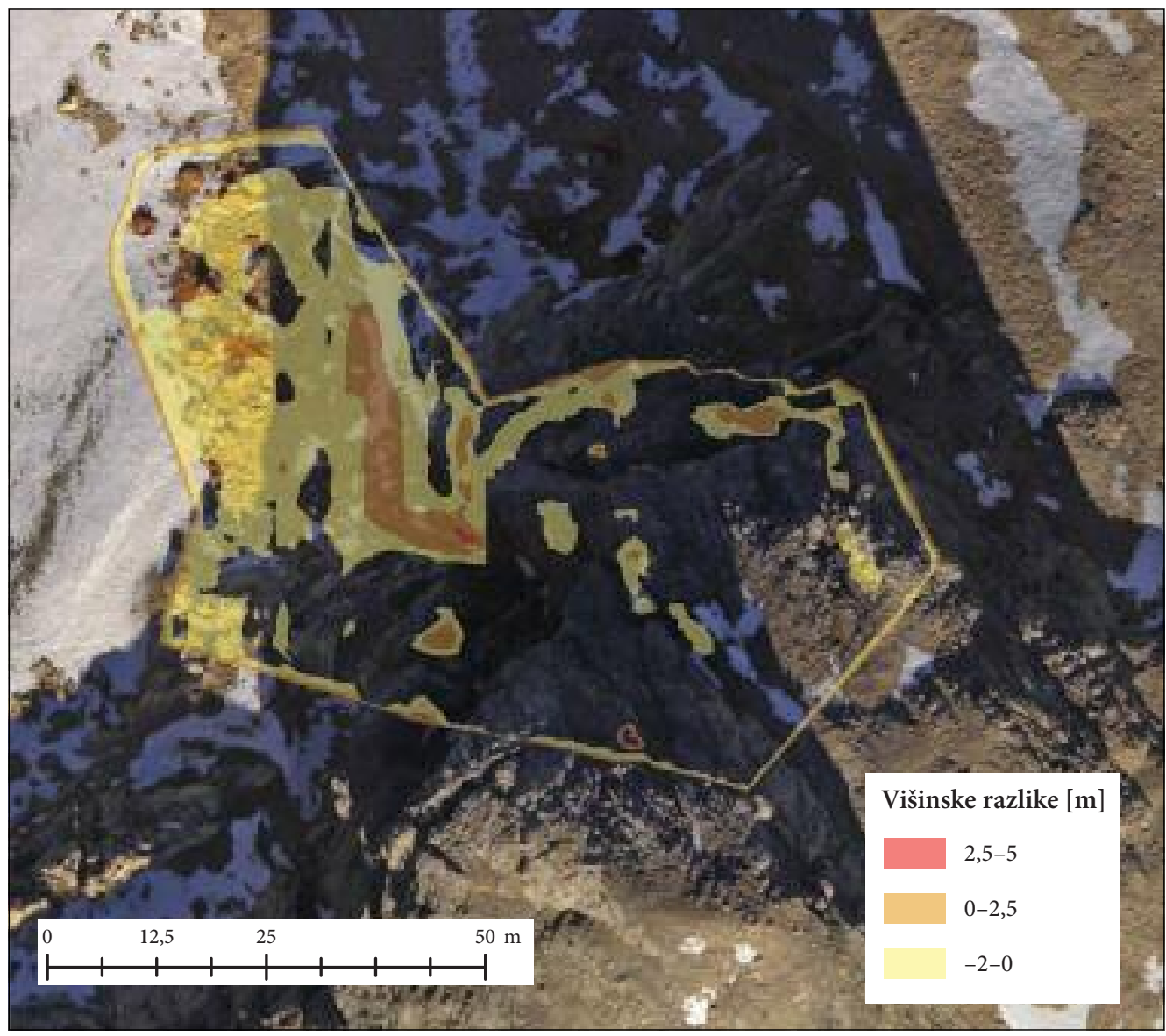

Slika 9: Ortofoto Glave pod Triglavom z vidnim podornim gradivom 18. septembra 2012.

Kot vidimo na sliki 9 je bil v izmeri točk iz leta 2006 sistematičen negativni višinski zamik. Na območju, kjer je na sliki 9 vidno, da je bilo leta 2012 nasutje, dobimo negativne višinske razlike do $-2 \mathrm{~m}$. To lahko deloma pripišemo višji snežni odeji na obravnavanem območju leta 2006 v primerjavi z letom 2012. Najbolj očitno se višja snežna odeja vidi na grbinah v levem (zahodnem) spodnjem vogalu slike 10. Deloma pa je v odstopanju skrita tudi napaka aerotriangulacije CAS 2006, ki smo jo omenili že v prejšnjem podpoglavju. Upoštevati moramo tudi to, da so originalni aeroposnetki CAS $2006 \mathrm{v}$ ločljivosti $0,5 \mathrm{~m}$, kar nam pri izdelavi DMR-ja z velikostjo celice $1 \times 1 \mathrm{~m}$ predstavlja težave ob prepoznavanju točk in posledično pri izmeri njihovih višin.

\section{Sklep}

Menimo, da so lahko stereoposnetki CAS dobra podlaga za spremljanje recentnih geomorfnih pojavov. $Z$ dostopnostjo zelo natančnih reliefnih podatkov aerolaserskega skeniranja Slovenije (Triglav Čekada, Bric in Oven 2012; Pegan Žvokelj, Bric in Triglav Čekada 2014), bo njihova tovrstna uporabnost še večja. Kot se je pokazalo v primeru hudournika Suhelj in odloma na Glavi, pa ni dovolj samo izračunati 


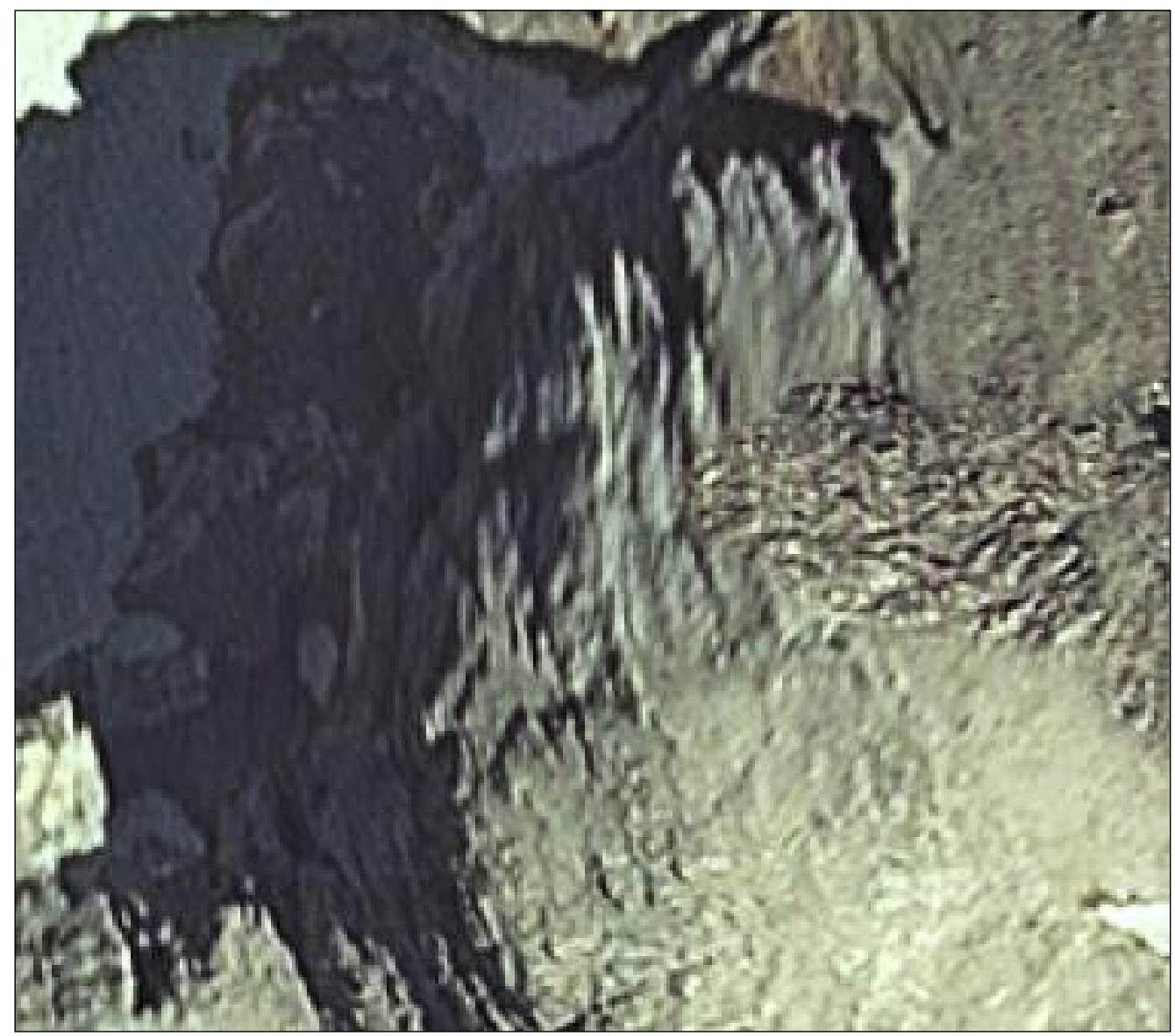

Slika 10: Izsek iz ortofota CAS 2006, ki prikazuje Glavo pod Triglavom pred podorom (vir ortofota: GURS).

višinske razlike $\mathrm{z}$ uporabo različno natančnih virov, kot sta aerolaserski DMR in fotogrametrični DMR, pač pa moramo upoštevati tudi izhodiščno natančnost vira (Razpisna ... 2008). Ta lahko namreč močno vpliva na izračune oziroma napake. Za CAS 2011 imamo v razpisni dokumentaciji (Razpisna ... 2008) podano dovoljeno srednje višinsko odstopanje na kontrolnih točkah $25 \mathrm{~cm}$, največja dovoljena višinska odstopanja pa so trikratnik te vrednosti. To pomeni, da s primerjavo uporabljenih časovnih nizov CAS, ne smemo iskati višinskih odstopanj, ki so manjša od $1 \mathrm{~m}$, saj so odstopanja do te višine lahko posledica dovoljenih višinskih odstopanj po postopku aerotriangulacije in natančnosti stereofotogrametrične izmere. $\mathrm{V}$ primeru višinske zamaknjenosti stereomodelov tudi zelo natančna ročna stereofotogrametrična izmera ne pomaga. To lahko rešimo le tako, da oba stereomodela ponovno orientiramo na podlagi identičnih oslonilnih točk, ki jih izmerimo na območju obeh stereomodelov.

Poleg tega moramo pri preučevanju visokogorja in iskanju manjših geomorfnih sprememb, upoštevati še različne naravne danosti posameznega snemalnega leta CAS, predvsem debelino snežne odeje $\mathrm{v}$ času snemanja; CAS se namreč ponavadi snema poleti, ko je v visokogorju lahko še dosti snega.

V prispevku smo predstavili štiri primere, pri katerih smo s pomočjo posnetkov CAS, iz dveh sicer ne preveč oddaljenih časovnih serij, spremljali geomorfno dinamiko. Razpoložljivost arhivskih posnetkov CAS za celotno državo ter za nekaj desetletno obdobje odpira možnosti za številne tovrstne analize. 
Zahvala: Avtorja se zahvaljujeva sodelavcem Geodetskega inštituta Slovenije, ki so izvedli ročni zajem $D M R$-jev za obravnavana območja v okviru čezmejnega projekta Slovenija-Avstrija "Naravne nesreče brez meja (NH-WF). Delo je bilo delno financirano tudi v okviru aplikativnega raziskovalnega projekta L6-4048 ter temeljnega raziskovalnega projekta J2-5479 Javne agencije za raziskovalno dejavnost Republike Slovenije.

\section{Viri in literatura}

Berk, S., Komadina, Ž. 2010: Trikotniško zasnovana transformacija med starim in novim državnim koordinatnim sistemom Slovenije. Geografski informacijski sistemi v Sloveniji 2009-2010, GIS v Sloveniji 10. Ljubljana.

Berk, S., Komadina, Ž. 2013: Local to ETRS89 datum transformation for Slovenia: triangle-based transformation using virtual tie points. Survey Review 45-328. Tolworth. DOI: 10.1179/1752270611Y.0000000020

Berk, S., Komadina, Ž., Triglav, J. 2011: Analiza skladnosti D48/GK- in D96/TM-koordinat zemljiškokatastrskih točk v Pomurju. Geodetski vestnik 55-2. Ljubljana. DOI: 10.15292/geodetski-vestnik.2011.02.269-283

Breg Valjavec, M. 2007: Premikanje struge Save in gramoznice na Jarškem produ. Divja odlagališča odpadkov na območju Ljubljane, Georitem 1. Ljubljana.

Breg Valjavec, M. 2013: Nekdanja odlagališča odpadkov v vrtačah in gramoznicah. Geografija Slovenije 26. Ljubljana.

Breg Valjavec, M., Ribeiro, D. 2014: Uporabnost zgodovinskih aeroposnetkov pri preučevanju pokrajinskih sprememb na ozemlju Slovenije. Digitalni prostor, GIS v Sloveniji 12. Ljubljana.

Erhartič, B., Jelenko, I. 2010: Vpliv naravnih nesreč na naravno in kulturno dediščino. Od razumevanja do upravljanja, Naravne nesreče 1. Ljubljana.

Frantar, P., Robič, M. 2009: Podori na območju slapa Čedca. Ujma 23. Ljubljana.

Gruen, A. 2012: Development and status of image matching in photogrammetry. The Photogrametric Record 27-137. Oxford. DOI: 10.1111/j.1477-9730.2011.00671.x

Ivnik, M. 2010: Geodetske meritve pri analizi padanja kamenja. Diplomsko delo, Fakulteta za gradbeništvo in geodezijo Univerze v Ljubljani. Ljubljana.

Kokalj Ž., Veljanovski, T. 2014: Izdelava 3R modela iz arhivskih letalskih posnetkov za digitalno retrospektivo porušenega Breginja. Digitalni prostor, GIS v Sloveniji 12. Ljubljana.

Komac, B., Zorn, M. 2007: Pobočni procesi in človek. Geografija Slovenije 15. Ljubljana.

Kraus, 1993: Photogrammetry, Volume 1: Fundaments and Standard Processes. Bonn.

Merchel, S., Mrak, I., Braucher, R., Benedetti, L., Repe, B., Bourlès, D. L., Reitner, J. M. 2014: Surface exposure dating of the Veliki vrh rock avalanche in Slovenia associated with the 1348 earthquake. Quaternary Geochronology 22. Amsterdam. DOI: 10.1016/j.quageo.2014.02.002

Mikoš, M. 1995: Vodnogospodarski načrt povodja Sava Dolinke - pritoki na območju od Jesenic do Rateč. Vodnogospodarski inštitut. Ljubljana.

Mrak, I. 2004: Minor karst landforms as an indirect method for datation - the case study valley Pod Košuto. Acta Carsologica 33-1. Ljubljana.

Naravne nesreče brez meja. Medmrežje: http://www.natural-hazards.eu/ (25.3. 2014).

Oštir, K. 2006: Daljinsko zaznavanje. Ljubljana.

Pegan Žvokelj, B., Bric, V., Triglav Čekada, M. 2014: Lasersko skeniranje Slovenije. Geodetski vestnik 58-2. Ljubljana.

Petek, F., Bric, V., Rotar, T. 2002: Uporaba starih letalskih posnetkov pri ugotavljanju sprememb rabe tal. Geografski informacijski sistemi v Sloveniji 2003-2004, GIS v Sloveniji 7. Ljubljana.

Razpisna dokumentacija za oddajo javnega naročila po odprtem postopku: Aeroposnetki in ortofoto 2009-2010. Geodetska uprava Republike Slovenije. Ljubljana, 2008. Medmrežje: http://www.gu.gov.si/ fileadmin/gu.gov.si/pageuploads/JVN_08/Aeroposnetki_in_ortofoto_2009-2010/Razpisna_dokumentacija.pdf (20.9.2014). 
Sodnik, J., Mikoš, M. 2006: Ocena magnitud drobirskih tokov v izbranih hudourniških območjih v Sloveniji. Acta geographica Slovenica 46-1. Ljubljana. DOI: 10.3986/AGS46104

Triglav Čekada, M. 2011: Možnosti uporabe zračnega laserskega skeniranja (LIDAR) za geomorfološke študije. Geografski vestnik 83-2. Ljubljana.

Triglav Čekada, M., Bric, V., Klanjšček, M., Barborič, B., Pavšek, M. 2013: Zračno lasersko skeniranje zasneženega površja. Raziskave s področja geodezije in geofizike 2012: zbornik predavanj. Ljubljana.

Triglav Čekada, M., Bric, V., Oven, K. 2012: Prvo vsedržavno lasersko skeniranje Slovenije. Geografski informacijski sistemi v Sloveniji 2011-2012, GIS v Sloveniji 11. Ljubljana.

Triglav Čekada, M., Zorn, M., Colucci, R. R. 2014: Površina Kaninskih in Triglavskega ledenika od leta 1893, določena na podlagi arhivskih posnetkov ter aerolaserskih podatkov. Geodetski vestnik 58-2. Ljubljana. DOI: 10.15292/geodetski-vestnik.2014.02.274-313

Zorn, M. 2002a: Podori na Dobraču. Geografski vestnik 74-2. Ljubljana.

Zorn, M. 2002b: Podori v slovenskih Alpah. Geografski zbornik 42. Ljubljana.

Zorn, M. 2008: Erozijski procesi v slovenski Istri. Geografija Slovenije 18. Ljubljana.

Zorn, M. 2012: Ujme v Pokokrju in Zgornji Savinjski dolini. Slovenija VI: Vodniki Ljubljanskega geografskega društva. Ljubljana.

\section{Summary: Determining the intensity of geomorphic processes using cyclical aerial photogrammetric measurements of Slovenia}

(translated by DEKS d. o. o.)

A set of cyclical aerial photogrammetric measurements of Slovenia (CAS) taken over the course of many years is available. Among other things, their use in geography has been connected with exploring changes in land use, studying environmental degradation, and determining specific physical geographical changes in the landscape, such as changes in glaciers and river beds. This article presents the usefulness of CAS for monitoring the intensity of slope processes. CAS stereoimages were used to measure the size of two rockfalls: one at Čedca Falls in the Kamnik-Savinja Alps and one on the slopes of Mt. Glava below Mt. Triglav. Also studied were terrain changes on the Birški plaz talus below Mt. Veliki Vrh on the Košuta Ridge in the Karavanks, and in the torrent valley of Suhelj Creek in the Upper Sava Valley.

Two sets of digital CAS images for 2006 and 2011 were compared. Using these images, a digital terrain models $(\mathrm{DTM})$ with $5 \times 5 \mathrm{~m}$ cell size ware produced. Despite automatic image matching procedures that enable automatic generation of DTMs are already available, such DTMs do not provide elevations as accurate as manual stereophotogrammetric data acquisition. Therefore, all of the DTMs were acquired manually at digital photogrammetric stations using a traditional stereophotogrammetric procedure. The orientation parameters of the 2006 CAS images were calculated as part of aerotriangulation of the entire photogrammetric block and transcribed in a D48/GK coordinate system with elevations. The DTM was also transformed into a new coordinate system in order to also perform the measurements on the same points in the 2011 CAS stereoimages, whose orientation parameters are transcribed in a D96/TM coordinate system. Transformations between D48/GK and D96/TM were made using a triangular transformation model (version 3.0). Errors in the production of DTMs primarily resulted from vegetation height estimations, shadows in CAS images, and position rounding of DTM points.

The Čedca Falls rockfall: At the end of May and June 2008, several rockfalls occurred at Čedca Falls in the Kamnik-Savinja Alps, which transformed the cliff behind Slovenia's tallest waterfall (130 m). After the rockfalls, the waterfall was only $30 \mathrm{~m}$ tall. In the trigger zone, the largest difference in elevation was $-64 \mathrm{~m}$ and in the accumulation zone the largest difference was $+48 \mathrm{~m}$. According to the estimates made, $288,880 \mathrm{~m}^{3}$ of material broke off from the original $0.95 \mathrm{ha}$ area. The broken-off material was deposited onto a 1.89 ha area and its volume was estimated at $271,730 \mathrm{~m}^{3}$. 
The Birški plaz refers to the extensive talus below Mt. Veliki Vrh $(2,088 \mathrm{~m})$ on the Košuta Ridge in the Karavanks. It lies below a collapse rock face measuring more than 7 ha from the largest Slovenian historical rockfall, with an estimated volume between 20 and 100 million $\mathrm{m}^{3}$. This rockfall is commonly connected with the 1348 Villach earthquake. The comparison of 2006 and 2011 DTMs revealed relief changes up to $\pm 10 \mathrm{~m}$. The entire area studied measures $40 \mathrm{ha}$, but the study focused on the eastern part of the talus, where larger changes were recorded (e.g., in a 1.1 ha area, where $38,240 \mathrm{~m}^{3}$ of material was deposited during the period studied, and in a 0.4 ha area, where $7,230 \mathrm{~m}^{3}$ of material was deposited; see Figure 5). The quantity of the material deposited in the period studied on the Birški plaz was significantly smaller than the rockfall material below Čedca Falls. This indicates a ratio between the »usual « collapsing of the rock material (high frequency, low magnitude) from cliffs and major geomorphic processes (low frequency, high magnitude) such as the Čedca Falls rockfall.

The Suhelj torrent: The basin of Suhelj Creek (a left tributary of the Sava Dolinka River near Podkoren) is characterized by great sediment production and sediment yield. Calculations indicate that the terrain has been lowered by 4 to $13 \mathrm{~m}$ in its upper part, and a full $98,700 \mathrm{~m}^{3}$ of rock has been removed from a 1.3 ha area. These values are considered greatly overestimated because the steep terrain caused many errors that primarily had to do with the spatial resolution of CAS.

The Mt. Glava rockfall: In 2011, part of the rock face on the northern slope of Mt. Glava (2,426 m) below Mt. Triglav collapsed. Unlike the cases described above, in this case the available aerial laser scanning (LIDAR) data made it possible to compare the $1 \times 1 \mathrm{~m}$ DTMs for 2006 and 2011 and subsequently study spatial changes in larger resolution. In 2011, a layer of rocks to $5 \mathrm{~m}$ thick with a volume of $124 \mathrm{~m}^{3}$ was deposited onto the talus below Mt. Glava, covering a $158 \mathrm{~m}^{2}$ area.

It can be concluded that CAS stereoimages form a good basis for monitoring recent geomorphic phenomena. Extremely detailed aerial laser scanning data of Slovenia will soon be made available, which will further expand their usefulness in these kinds of cases. However, one must also pay attention to potential errors because it is not enough to merely calculate the differences in elevation using sources that vary in precision, such as aerial laser scanning DTMs and photogrammetric DTMs, but the initial precision must also be taken into account because it can significantly affect the calculations. In addition, when studying high mountainous areas, it is also necessary to take into account the different natural conditions of the specific year the CAS were made, especially the depth of the snow cover at the time of measurements; CAS are usually made in the summer when there may still be a lot of snow in the high mountains. The availability of archival CAS images for the entire country over a period of several decades opens new opportunities for many analyses of this type. 